Dicenda. Estudios de lengua y literatura españolas

ISSN-e: 1988-2556

https://dx.doi.org/10.5209/DICE.65007

\title{
"Clarín" cosmopolita frente a la literatura americana: erudición, nacionalismo y tensiones críticas en la defensa del canon español
}

\author{
Mariano Saba ${ }^{1}$
}

Recibido: 10 de octubre de 2017 / Aceptado: 19 de junio de 2018

Resumen. Dentro del campo intelectual español del siglo XIX, Leopoldo Alas "Clarín" ocupó el rol privilegiado de crítico de actualidad capaz de organizar el canon deseable de la literatura moderna de su patria. Sin embargo, ante la crisis finisecular y la pérdida de las últimas colonias, diferentes zonas de la praxis clariniana revelan familiaridades notables con la erudición más conservadora. Desde la reivindicación del canon del Siglo de Oro a la reacción contra los modernismos americanos, Clarín exhibe un nacionalismo pocas veces estudiado para la comprensión cabal de su producción crítica.

Palabras clave: Clarín; Siglo de Oro; nacionalismo; modernismo; Rubén Darío.

[en] Cosmopolitan "Clarín" and American literature: erudition, nationalism and critical tensions in the defense of the Spanish canon

\begin{abstract}
In the nineteenth-century Spanish intellectual field, Leopoldo Alas "Clarín" occupied the privileged role of critic capable of organizing the desirable canon of modern literature. However, facing the crisis and the loss of the last colonies, different areas of the Clarinian praxis reveal remarkable familiarities with the more conservative erudition. From the claim of the Golden Age canon to the reaction against the American modernisms, Clarín exhibits a nationalism rarely studied for the complete understanding of his critical production.
\end{abstract}

Keywords: Clarín; Spanish Golden Age; nationalism; modernism; Rubén Darío.

Sumario: 1. Introducción: la crítica clariniana y la construcción del canon nacional; 2. La estrategia erudita: sobre el concepto de hispanidad; 3. Encrucijada para un cosmopolita: la acechanza del mal francés; 4. Los modernismos americanos y la reacción nacionalista de Alas; 5. A modo de conclusión.

Cómo citar: Saba, Mariano (2019). "Clarín" cosmopolita frente a la literatura americana: erudición, nacionalismo y tensiones críticas en la defensa del canon español, en Dicenda. Estudios de Lengua y Literatura Españolas, 37, 343-362.

\section{Introducción: la crítica clariniana y la construcción del canon nacional}

Más allá de sus indiscutibles valores como narrador, la figura de Leopoldo Alas se recorta sobre el panorama privilegiado en que nacía la pionera organización del campo

1 CONICET / Instituto de Filología y Literaturas Hispánicas "Dr. Amado Alonso" - Universidad de Buenos Aires marianosaba@gmail.com 
crítico español. En esa compleja instancia de constitución de la crítica nacional, Clarín proyecta un deslinde de responsabilidades entre la erudición academicista (encabezada por Menéndez y Pelayo) y la lectura de actualidad — renovadora y cosmopolita-, encarnada por sí mismo. Sin embargo, y más allá de la aparente divisoria de aguas, en ciertas zonas de su obra Alas parece descubrirse como un representante curiosamente "conservador" dentro del campo intelectual que entonces bregaba por la reivindicación de un imperio simbólico sobre las ruinas de otro imperio histórico y material.

La paradójica "ortodoxia" de Alas en este sentido puede leerse en la clave de cierto nacionalismo semejante en sus postulados defensivos a los emitidos por la erudición pelayana. A pesar de su ideario liberal y republicano, Clarín expresa algunas cercanías con ese pensamiento a priori antagónico. En algunos pliegues de su obra (donde a veces sus juicios críticos contrastan con postulados vertidos en la intimidad epistolar) se pueden identificar las más notorias contradicciones entre el cosmopolitismo clariniano - tan cercano al deseo de modernización y de apertura-, y su esporádica defensa del canon áureo nacional, núcleo clásico de redención patria. Esa defensa de lo "genuino" se produce en Alas ante la siempre temida otredad foránea, se trate ya de las modas parisinas o - sobre todo- del modernismo americano (en su amplio espectro desde Rodó a Darío o Martí).

Así, lo que se buscará comprobar es si en esas zonas tendientes a la defensa del canon imperial y a la resistencia ante novedades emancipadoras, no existe en Alas un diseño crítico personal capaz de vincularse de manera oblicua con la tradición nacionalista más conservadora. Es decir, un contorno que si bien lo libera de las exigencias eruditas, le permite inscribirse de otro modo en el recurrente debate sobre la nostalgia por el canon pasado (desde Cervantes al teatro áureo) y sobre su controvertida vigencia modélica en medio de un horizonte literario donde diversos tipos de "cosmopolitismo" obligaban a redefinir la cultura nacional española.

\section{La estrategia erudita: sobre el concepto de hispanidad}

A pesar de su supuesta distancia con respecto al canon del Siglo de Oro (se trate de la comedia nueva, o de Cervantes y Quevedo ${ }^{2}$ ), es inocultable que Alas — sin reconocerse miembro del campo erudito- mantuvo siempre un franco interés en la incidencia del legado áureo dentro del campo literario de su tiempo. Tal es así que algo de la conciencia de ese pasado — en contraste con la "mediocridad" que observaba en su contextopuede haber estimulado su viraje crítico finisecular hacia una mayor resignación con

\footnotetext{
Ejemplo notable de cómo Alas busca señalar cierta ligazón con el pasado áureo nacional —incluso más allá del género teatral- puede verse en su prólogo a Palique. Ahí se ocupa de insertar su praxis crítica dentro de la tradición más longeva del humorismo español. A tales efectos, y luego de evocar al Archipreste de Hita, afirma: "Hay un modo de gracia española, de sátira y vis cómica castellana que no se parece a nada de lo que pueden ofrecernos las literaturas extranjeras. No son muchos, más bien pudiera decirse que son muy pocos, los escritores españoles que tienen este matiz del ingenio al que me refiero y cuyas cualidades distintivas, cuyo tinte particular no cabe explicar con los términos comunes de la retórica y de la estética. (...) Esta alegría satírica, este gusto cómico de algunos españoles tiene el mérito de criarse en terreno poco a propósito, rodeado de una seriedad enemiga, de una solemnidad formal, de una morgue..." (Alas, 2008: 768-769). Clarín invita a ver este matiz de la gracia cómica sobre todo en el Quijote de Cervantes y en algunas de sus Novelas ejemplares. Y también en este mismo libro parece caracterizar a sus paliques con el sesgo satírico del humorismo español, asociándolos así con la ineludible monumentalidad de Cervantes - y de Quevedo o, más tarde, de Larra-, antecedentes declarados de esa comicidad.
} 
respecto a la expectativa renovadora que había tenido en cuanto a la literatura nacional. En este sentido vale asociar el caso clariniano con la conceptualización que Pozuelo Yvancos (2000) ha señalado en su estudio sobre Amador de los Ríos, quien paradójicamente había sido profesor de Alas durante el curso de 1873 en la Universidad de Madrid. Pozuelo alude allí a la antinomia foráneo/genuino que atraviesa todo el proyecto de la Historia crítica de la literatura española. Una dicotomía que localizaba lo popular lejos de lo culto, que ya había encubierto en el siglo XVIII la antinomia francés/español y que seguiría avanzando hasta homologarse con la oposición ortodoxia/heterodoxia. Ya sea como herramientas, o como lugares comunes a romper, tanto Menéndez y Pelayo como Clarín se hacen eco muchas veces de esta característica al tratar la relación entre historia literaria y nación: el canon pretérito explica su carácter basal de la literatura nacional por tratarse sobre todo del resultado "genuino" de un sustrato histórico popular, y no de la invasión "foránea" que parece subvertirlo todo en el ámbito de la modernidad. Esta coincidencia en el factor aglutinante del pasado literario español permite un acercamiento notable entre escritores de franca disidencia política y religiosa, como era el caso de Alas y del erudito santanderino. Sin embargo, como factor común en el disenso, explica a las claras la manera en que la idea de una historia literaria permitió la existencia común de un nacionalismo cultural defensivo de lo hispano.

La idea de hispanidad encuentra en la reivindicación del antiguo capital literario un modo cohesivo de ligar la fragmentación nacional provocada por las últimas crisis coloniales. Más allá de los signos políticos que orientaran la tarea de los intelectuales españoles de fines de siglo XIX, la hispanidad funcionó como un antídoto capaz de aunar en una misma sanación cultural dolores tan distintos como los del erudito Menéndez y Pelayo, católico y monárquico, y los de Clarín, liberal y republicano. Ahora bien, ¿qué características ha debido tener esa hispanidad para congeniar con la recepción multiforme de la crisis de fin de siglo español? Álvarez Junco (2005) retoma ciertas ideas de Hobsbawn sobre el doble programa político que condujo a los nacionalismos europeos, y afirma para el caso español cierto fracaso general en los efectos de ese proyecto:

...la situación del nacionalismo español en las últimas décadas del siglo XIX se resumía de manera sencilla: había fracasado en ambos terrenos. En el de la reforma política interna, la revolución liberal estaba congelada; en el ámbito exterior, el imperio colonial se había perdido o se hallaba en trance de perderse (508).

Ante la caída de ese vector, surgen hacia fin de siglo movimientos concretos como los intentos de una nueva expansión imperial hacia África. Pero emergen además, dentro del plano simbólico, no sólo las historias de las literaturas nacionales, sino también la reivindicación de una hispanidad literaria que buscaría religar la antigua metrópoli con América, la cual se mostraba cada vez más atraída por centros de innovación como París. Ante la pérdida territorial, asegura Álvarez Junco, el españolismo — sea basado en la religión, como quería la derecha, o en el progreso de la civilización, como insistía Castelar - reclamaba su retorno al eje imperial europeo no sólo batallando militarmente, sino también por medio de la crítica. Un ejemplo destacado con respecto a esta contienda de discursos fue la polémica entre Juan Valera y Rufino José Cuervo. Estudiado detalladamente por José del Valle (2002), el feroz intercambio entre ambos autores deja al descubierto cómo el erudito Valera - autor de las Cartas americanas (de 1889) que intentaban acortar distancias entre 
ambas orillas - , ataca a Cuervo por augurar una fragmentación ineludible del lenguaje español y, por lo tanto, una diferenciación del español "americano". Ofuscado porque Valera no corresponde al criterio científico con que él intenta desarrollar la discusión, Cuervo llega a declarar:

[Valera] pretende que las naciones hispanoamericanas sean colonias literarias de España, aunque para abastecerlas sea menester tomar productos de países extranjeros y, figurándose tener aún el imprescindible derecho a la represión violenta de las insurgentes, no puede sufrir que un americano ponga en duda el que las circunstancias actuales consientan tales ilusiones: esto le hace perder los estribos y la serenidad clásica. Hasta aquí llega el fraternal afecto (citado en Del Valle, 2002: 67-68).

Sin dudar de que el problema lingüístico revelaba una especie de colonialismo literario en ciernes, Cuervo reacciona ante el centro ideológico de los postulados de Valera al respecto: "he frequently insisted on the close relation between language and spirit of the nation; for him, the evolution of language was a reflection of the historical development of the national spirit" (Del Valle, 2002: 68) ${ }^{3}$. El espíritu nacional plantea un desarrollo análogo al del habla nacional: en cuanto los intelectuales americanos como Cuervo comienzan a postular allí un hiato, lo que está en juego para la erudición española es no sólo el idioma, sino el cuerpo mismo de la nación. La respuesta será, entonces, hispanidad: los eruditos se erigen así como defensores de esa unión inhallable dentro de lo territorial pero indiscutible en términos "metafísicos" y de lenguaje. Menéndez y Pelayo, en esta línea, sigue el esfuerzo por la vinculación "lingüística" de lo perdido. En ocasión del cuarto centenario del "descubrimiento" de América, la Real Academia Española encarga al santanderino su Antología de poetas hispanoamericanos (1893-1895)4. Tal como opina Olguín (1957):

3 Tal como señala Campos López (2015) en su artículo sobre los primeros promotores del concepto de hispanidad: Valera "defendió persistentemente la idea de unidad superior que la sangre, lengua, literatura y cultura daban a las naciones hispanoamericanas y su propia personalidad entendida como prolongación de la cultura hispánica en esas otras tierras, a pesar de la independencia política" (42), lo cual demuestra su sintonía con los postulados de Menéndez y Pelayo. También Ashhurst (1980) subrayaba esta idea en su ya clásico estudio sobre la literatura hispanoamericana en la crítica española: "Como Valera tenía sentimientos tan fuertes sobre la lengua como la base de unión entre España e Hispanoamérica, resulta muy lógico que viera la literatura en Hispanoamérica, antes y después de las guerras de la independencia, como proyección y contribución integral al cuerpo total de la literatura española. En ocasiones sin número expresó esta creencia: ‘ ... es resultado satisfactorio el reconocer que la literatura española y la hispano-americana son lo mismo" (118). Valera concibe como inentendible el antagonismo entre Europa y América siendo esta última una especie de triunfo de la civilización europea y cristiana sobre la naturaleza bravía. La aparente ingenuidad de este criterio enmascara los mecanismos propios de un colonialismo simbólico empeñado en redimir la caída imperial. Así opina también Carbonell (1994) cuando indica el modo "unificador" con que se sitúa frente a América la erudición española — en su amplio espectro desde Menéndez y Pelayo a Valera—. Clarín, por su parte, lee en la Cartas americanas un modo de insertar el humorismo de Valera en el propio ejercicio erudito: "consiste el artificio en la habilidosa narración o descripción de lo nimio, de lo ridículo o extravagante con una especie de cándida seriedad" (en Carbonell, 1994: 160). Debiera ser significativa la radicalización clariniana en torno a la posición erudita con respecto a América: allí donde Valera persigue el objetivo "nacionalista" de fomentar la unidad, Alas da un paso más allá y asimila buena parte del logro de sus cartas con el humorismo sobre lo "nimio". Tal vez no haya manera más oblicua de desestimar el objeto de las Cartas americanas.

4 Según Cabo Aseguinolaza (2012), “el objetivo primordial de la antología era el de definir una apropiación o incorporación de las letras americanas al ámbito de la literatura española" (401), comprendiéndose que "la noción de lo que era y debía ser la literatura española se articuló a partir de la exclusión de lo foráneo y de lo heterodoxo" (401). 
El encargo ofrecía al patriotismo de D. Marcelino una ocasión de perlas para reconfortar los ánimos españoles recordando que no todas sus glorias eran del pasado, pues todavía su lengua y su cultura estaban dando ricos resultados en América. La Antología puede considerarse, de este modo, como una expresión más del vehemente afán de defensa e ilustración de la Hispanidad que impulsa toda la obra del gran crítico (28).

Como puede notarse, y retomando lo mencionado en el primer apartado en cuanto a las obligaciones entre la funcionalidad erudita y el nacionalismo español, el concepto de hispanidad es arma que se esgrime no sólo contra la caída de los últimos dominios imperiales sino también ante la emancipación literaria de territorios que hacía tiempo habían dejado de ser colonias. Clarín, sin embargo, no siendo un defensor especializado del canon pretérito, y aún mostrándose una y otra vez como ajeno al campo erudito, se sitúa cerca de la reacción conservadora de Valera y Menéndez y Pelayo. En su reseña del Ariel de Rodó para Los Lunes del Imparcial expresa con cierta melancolía:

Sí, hace muchos años, cuando menos se quería por allá a los españoles, recientes todavía los dolores de la separación, los literatos, especialmente los poetas, solían inspirarse en nuestros autores más célebres, como Quintana, Espronceda, Zorrilla; después se vio que nuevas generaciones iban olvidando esta sugestión española, para entregarse a la de otras literaturas europeas, principalmente la francesa (citado en Dobry, 2010: 67).

Pero cabe destacar que esta reseña de 1900 no expresa cabalmente la intensidad de reacción que Alas había demostrado aún antes con la pérdida de las colonias. Así lo explica Lissorgues (1979) cuando dice que después del "desastre” Alas

se siente hondamente herido, como español, y en un primer momento participa de la reacción nacionalista que entonces domina. Después de Cavite, el primer ministro inglés, Salisbury, ha declarado que "ciertas naciones cristianas [España] están moribundas" y tienen que "entregar su territorio a otras naciones fuertes, vivas, nuevas"; Clarín reacciona con suma violencia, defendiendo a España: "Una nación no muere ni agoniza porque le queman un poco de madera podrida. Una nación es ante todo un alma, y el alma de España, no agoniza" (72).

Entre sus múltiples opiniones tras la guerra con Estados Unidos, Clarín deja ver en la esfera pública de la crítica su enorme coincidencia con las estrategias de redención simbólica de los eruditos. Según Lissorgues, Alas — antes de perder a Cuba en la asimilación anglosajona - augura la necesidad de sostener "la realización de lo que llamaba en 1890 'esta bendita fraternidad literaria de América y España'..." (1979: 73). Así su voluntad es salvar el lazo entre América (¿hija?) recuperando para las Repúblicas hispanoamericanas "una estrecha alianza con la madre común, con esta pobre España” (en Lissorgues, 1979: 73). Su nacionalismo en este punto sólo irá entibiándose cuando proponga tiempo después ocuparse de la reconquista agrícola de la propia península antes de perderse en el lujo de dominios coloniales insostenibles (Lissorgues, 1979: 74). Sin embargo, a pesar de la atenuación de sus embates, 
algo del nacionalismo clariniano se robustece tras $1898^{5}$. Prueba incontrastable de ello es el modo en que su respeto por el pasado literario imperial convive de manera controvertida con todo intento de modernización proveniente de Francia o de esa misma América fraterna que veía distanciarse como un vástago emancipado ${ }^{6}$.

\section{Encrucijada para un cosmopolita: la acechanza del mal francés}

Como se ha mencionado ya, muchas veces es el doblez de la intimidad, entre lo público y lo privado, el espacio que revela la tensión clariniana originada por la colisión de lo tradicional con la renovación. El epistolario escenifica nuevamente la doble estrategia: en la intimidad epistolar Clarín se desliga de las competencias eruditas sobre el Siglo de Oro, pero al mismo tiempo opera desde la crítica diaria objetivando dicho canon y valorando su fuerza identitaria. En carta desde Oviedo dirigida justamente a Menéndez y Pelayo, y fechada el 19 de septiembre de 1894, Alas se autoexcluye expresamente del plano erudito. Con motivo de la visita del hispanista italiano Arturo Farinelli, le comenta al estudioso santanderino:

A mí me caló desde el primer momento y tuvo la delicadeza de no echar de menos en mí al erudito que no hay ni con cien leguas. Pero congeniamos, estábamos de acuerdo en religión, tolerancia, Pelayismo y en punto a Carlyle, Macaulay, Renan, Taine, y si no en lo de Lope y Calderón, esto por culpa de que yo no he estudiado bastante ni a uno ni a otro (Menéndez y Pelayo, 1943: 93) .

Y sin embargo, ya desde poco tiempo después de las celebraciones de 1881, Alas venía promoviendo cierto viraje hacia una apología del teatro clásico español, la cual se iba a sostener de manera esporádica pero recurrente aún en tiempos posteriores. Su ensayismo crítico da cuenta una y otra vez de la exhibición pública de su

5 Puede considerarse la postura individual de Alas como inmersa en el ambiente colectivo que describe Núñez Seixas (2018) en su análisis del nacionalismo finisecular ante el Desastre: "Al mismo tiempo, la España que se convertía en nación europea mantenía trazas posimperiales. Las últimas colonias del Caribe (Cuba y Puerto Rico) se incorporaron desde mediados del siglo XIX al imaginario nacional como una «España de ultramar»: no eran vistas como meras colonias, sino que eran consideradas como dos territorios más de la comunidad política española. Tras 1868, los separatistas cubanos fueron vistos como esclavos cimarrones que pretendían amputar un miembro al cuerpo de la nación e imponer la anarquía racial. La guerra hispano-norteamericana de 1898 favoreció el florecimiento de una retórica patriótica que también alcanzó a los estratos populares” (272).

6 Es paradójico que Lissorgues recuerde también las imágenes utilizadas por Clarín en 1895, cuando este se empenaba en atacar los errores de la política colonial tradicional. Alas citaba por entonces a Bentham y a sus ideas sobre los equívocos producidos por el concepto de "madre-patria". Este concepto había entrañado siempre imposiciones a las colonias fundadas en la metáfora de la dependencia filial. Y ante ello comentaba Clarín: "Sí, ese es el error, los cubanos no son nuestros hijos, son nuestros hermanos" (Lissorgues, 1979: 69). Este elemento puede tenerse en cuenta dentro de las coordenadas íntimas en que se entrecruzan los itinerarios de lo privado y de lo público, y en cuyo interior se superponen los deberes biográficos de lo paterno-filial, con las reglas "vinculares" del campo cultural (desde la herencia condicionante de la épica "familiar" - tanto de la historia literaria como del propio canon medieval y áureo-, hasta la caída de la autoridad "materna" de la literatura nacional a la que se pertenece)-

7 Ricardo Gullón (1978) también se ha percatado de esta autoexclusión clariniana del campo erudito y de su inscripción dentro de la crítica de combate al virus "moderno" y foráneo de las modas y de la decadencia. Llega a contrastar puntualmente la figura del novelista con la del erudito santanderino en términos de complementariedad: "La Providencia hace bien las cosas, y lo que faltaba a cada uno de ellos lo otorgó al otro, para que sus obras respectivas, completándose, reunieran la mejor cosecha crítica del siglo XIX español. Don Marcelino, con más gusto para el estudio de lo pasado, por la historia literaria; Alas, curioso por lo presente, por la literatura actual..." (116). 
sapiencia con respecto al núcleo del canon áureo y, por lo tanto, de su respeto ante la vigencia del centro identitario tradicional de la cultura nacional. En Sermón perdido, de 1885, opina sobre la Poética de Campoamor y sostiene: "Si Tirso resucitara, fraile y todo, sería probablemente, dado su teatro, el jefe de la escuela literaria a que tengo la honra de pertenecer" (2003b: 555). Vuelve a aparecer una actitud defensiva del teatro barroco en Nueva campaña, publicado en 1887. Allí mismo lanza una diatriba contra el Estado que no protege ni incentiva la representación de los clásicos:

Una de las mejores cosas que tiene que conservar España es su teatro. Entre todos los teatros habidos, (no digo por haber), sólo estos dos, el antiguo griego y el inglés del Renacimiento, pueden competir con el nuestro; pregunten ustedes por ahí fuera, y los que entienden de estas cosas les dirán. ¡Oh! El teatro español de Lope y Calderón, de Tirso y Rojas, de Alarcón y Moreto... ¡cosa buena! (2003a: 848).

Clarín señala que no hay que leer este teatro porque lo digan los eruditos, sino porque "Dios quiere que sea así, que tengamos esa reliquia preciosa entre tantas lacerías tradicionales" (848). En el ya mencionado folleto de 1890, Rafael Calvo y el teatro español, Clarín arremete con nostalgia:

Hablando con más formalidad, me atrevo a sostener que el siglo XIX no ha dado a España un renacimiento dramático que podamos ofrecer al estudio y a la admiración de los extranjeros, como descendiente legítimo del gran teatro que es admirado en todos los países de alguna cultura estética, al igual de los más famosos teatros (Alas, 1890: s/p).

Como puede notarse, la preocupación de Clarín por el Siglo de Oro y por su teatro como centro canónico venía de larga data y no resultaba tan liviana como la que postularía en su ulterior carta de 1894 a Menéndez y Pelayo. Como destaca Oleza (2001), es indudable que el autor consideraba al Barroco como "la iniciación a la literatura europea al mismo tiempo que el núcleo de la tradición nacional” (25). Es por ello que cierto españolismo se irradia de forma contundente en esa zona de su praxis crítica. A fines del siglo XIX Alas parece cobrar conciencia nítida del rol aglutinante que ciertos hitos del canon áureo implican para la fragmentada cultura española. Habiendo pugnado por una difícil renovación de las letras españolas, y habiendo adherido a un naturalismo proveniente de Francia cuyo materialismo culminó por distanciarlo, termina optando por cierto nacionalismo (tal vez algo más blando que el de algunos de sus congéneres). Un nacionalismo a través del cual reclama la importancia de rescatar las glorias literarias del pasado español y ponderar sus vigencias en la producción de actualidad. La contrapartida de ese salvataje sería una franca actitud defensiva ante la modernidad y sus modas parisinas o americanas.

En esta línea Clarín se muestra corrosivo ante la escasa incorporación de traducciones de la literatura española contemporánea en la Francia de fines del siglo XIX. Se mofa en varias oportunidades de la ignorancia que el público francés y sus críticos tenían en cuanto al panorama literario español de su tiempo. Según Cabo Aseguinolaza (2012):

Le irritaba, en suma, la subsidiaridad y distancia que delataba la visión precipitada y un punto condescendiente que llevaba, a su juicio, a tratar a los escritores 
españoles "como si fueran poetas salvajes de una isla recién descubierta, que urge hacer conocer al mundo" (197).

Alas no ignoraba el papel que París estaba jugando en cuanto a la internacionalización de las letras. Sin embargo, y a pesar de sus matices al respecto, "desarrolla todo un discurso crítico sobre las limitaciones del cosmopolitismo cultural francés y su sesgo nacionalista" (Cabo Aseguinolaza, 2012: 197-198). Es curioso sin embargo que esa sensación frustrante ante la autoridad "censora" de Francia, empeñada en desvalorizar el capital cultural español, fuera a reproducirse de manera paradójica en el cosmopolitismo clariniano y en su vínculo con América, tan semejante en relación con la problemática de sus filtros nacionalistas para con la otredad. Si a fines del siglo XIX la intelectualidad hispánica percibe a Francia como un "elemento distorsionante en la relación española con América” (Cabo Aseguinolaza, 2012: 388) ${ }^{8}$, Clarín no resulta una excepción. Tal como los eruditos Menéndez y Pelayo y Valera habían rechazado la hegemonía de la influencia artística proveniente del cosmopolitismo francés ${ }^{9}$, así también Alas endurecería sus modos con relación al poderío expansivo de la autoridad parisina. En este sentido parece ejemplar la demoledora reseña de 1898 que Clarín escribe en el Madrid Cómico con respecto a la revista literaria La Neblina, del escritor peruano José Santos Chocano. Acusa recibo de su lectura y expresa:

¿Qué me parece? Muy mal. Rematadamente mal. ¿Cómo ha de parecerme que muchachos de ilustración notable (...) se empeñen en parecer tontos, y tontos reflejos imitando las bobadas más insulsas de la juventud parisiense literaria en su parte más ignorante, sosa y presuntuosa? (citado en Ashhurst, 1980: 149).

Y añade allí lo que ocupará el final de este trabajo: un alerta sobre el vehículo americano que en su opinión portaba el estigma parisino de la moda: “¿Pero todavía estamos ahí? ¿Bajo el poder de los bobazulicones?” (149). Sin mencionar a Rubén Darío, el didactismo paterno y "nacionalista" con que Clarín ataca a Chocano pone la atención sobre el servilismo "azulino". "¡Oh, quién diera a los azules de este y de ese continentes coger las chispas de Cervantes...!" (150), afirma Alas recurriendo nuevamente a la cantera áurea de lo "genuino" español. Y agrega que si las revistas americanas no se ocupan de enlazar con la tradición clásica de la madre patria, se tornan simples "focos de servil imitación francesa (...) que están infestando esas hermosas repúblicas hispanoamericanas” $(150)^{10}$.

8 La redención de ese desequilibrio frente a Francia subyace aún a hipótesis posteriores como la de Guillermo de Torre, quien definió a Madrid como meridiano del hispanoamericanismo equilibrado, en contraste con el meridiano de lo europeo que sería París. En esta línea, tal como señala Cabo Aseguinolaza (2012), la emergencia de la literatura hispanoamericana como entidad diferenciada no sólo conlleva el riesgo de la pérdida sino de la sustracción del capital por parte de otro ámbito. Como si el peligro de ese divorcio fuera sobre todo haber sido "inducido por horizontes de influencia más prestigiosos como, muy particularmente, el francés" (393).

9 Al respecto puede consultarse el ya mencionado artículo de Campos López (2015) sobre la acuñación pionera de la idea de "hispanidad".

10 Esto puede asociarse con el encuadre antimodernista que condiciona buena parte de la crítica española finisecular. Como señala Litvak (1990): "Otra de las posturas modernistas que se veía con recelo era su cosmopolitismo que parecía amenazar los valores nacionales. El mundo cosmopolita de esa literatura carecía de lazos sólidos con la patria y sobre todo, había abierto la puerta a ese "decadente" entusiasmo por lo extranjero, erosionando con ello las sanas virtudes nacionales" (121-122). No deja de indicar Litvak la postura particular de Clarín en esa situación, atacando de manera recurrente el "afrancesamiento" de los latinoamericanos. 
Como podrá notarse, la senda americana muestra entonces para Clarín varias "direcciones": una deseable y otra desviada. La deseable ligada a la herencia; la desviada, al "taller del cursi modernismo importado" (150). Sobre tales vías (y sobre una tercera "indecible") se tratará en el apartado próximo, buscando ligar cada una de esas alternativas con nombres americanos significativos dentro del controvertido "cosmopolitismo" clariniano: Rubén Darío, José Enrique Rodó y José Martí.

\section{Los modernismos americanos y la reacción nacionalista de Alas}

Desde inicios del siglo XIX puede rastrearse la insistencia del pensamiento eurocéntrico en la autorreflexión hispánica. Tal como menciona Álvarez Junco (2005), ya desde esos momentos existe una pérdida de credibilidad en la monarquía estrechamente ligada con su "incapacidad para evitar que se escapase de sus manos el imperio americano" (503). Sin embargo, y como había ocurrido desde mucho tiempo antes, la acusación a América por la decadencia imperial resultó una constante defensiva dentro del nacionalismo español:

Lejos de magnificar el descubrimiento y conquista del Nuevo Mundo, dominaba incluso una cierta tendencia a culpar aquella expansión imperial de muchos de los males de la patria, tendencia que la mitología histórica inventada por los liberales no hizo sino reforzar (Álvarez Junco, 2005: 503).

A efectos de la hipótesis que aquí se viene esbozando, y para el caso concreto de Alas, puede recordarse que la culpabilización de América por el atraso español tuvo su revés "liberal" en el posterior reclamo de un capital cultural (y literario) que ya no pertenecía de ningún modo a la antigua metrópoli. Si bien es cierto que los liberales españoles desestimaron rápidamente la pérdida de las últimas colonias, no ocultaron su estupor ante la caída de la incidencia española en el mundo exterior. La erosión del colonialismo denunciaba claramente el fracaso de la revolución liberal en su intento por traducir complejos valores etno-patrióticos que provenían del absolutismo monárquico al lenguaje de cierto nacionalismo moderno. Es entendible, entonces, que tanto Clarín como Valera - como también otros exponentes del amplio espectro de la intelectualidad española de fin de siglo-, hubieran hallado en la filiación españolista de la literatura americana una forma de sublimar la fallida continuidad histórica que el proyecto liberal había intentado sostener con las naciones emergentes.

Por otra parte, América configura claramente en el último cuarto del siglo XIX un núcleo de auto-legitimación cultural. En términos de Cabo Aseguinolaza (2012), "América significa en cierto modo, y por encima del silencio o la omisión, una dislocación y una proyección innovadora de la escritura en español" (340). Forma inocultable de contrarrestar ese riesgo de "emancipación" literaria, la crítica española despliega estrategias evidentes para subestimar esa novedad de América. Un caso ejemplar es el modo en que Leopoldo Alas desestima la figura de Rubén Darío. En este sentido, Clarín "representa la reacción de otros que desdeñaban las letras americanas como una derivación epigonal y provinciana de las españolas en las que se exacerbaban los peores defectos de estas" (Cabo Aseguinolaza, 2012: 399). Así Alas 
critica a Valera por su "diplomática" recepción de ciertos autores americanos ${ }^{11}$, y pregona a su vez la necesidad de recuperar cierta definición europea de la literatura española, contrarrestando la benevolencia francesa ante el hispanoamericanismo en auge. Nuevamente el término controvertido que saldrá a escena es el de cosmopolitismo: un concepto que dentro de la praxis clariniana cobra sentidos múltiples, proliferantes no sólo ante la colisión entre literatura americana y apropiación española, sino también en el doblez mismo de su pensamiento íntimo y de sus abiertas intervenciones críticas.

No cabe ninguna duda de que en el campo intelectual de la España finisecular, la figura pública de Leopoldo Alas constituía un ejemplo de cosmopolitismo crítico muchas veces tolerante y receptivo de las influencias renovadoras provenientes del extranjero. Es comprensible en este sentido que uno de sus biógrafos pioneros, Juan Antonio Cabezas, publicara durante el año de 1936 en Madrid la vida del autor ovetense titulándola Clarín, el provinciano universal. Ya por ese entonces Cabezas cifraba la característica central de la crítica de Alas en una definición dicotómica entre localismo y cosmopolitismo. Argumentaba al respecto:

... a veces zurra a uno entre ciento, con objeto de que cada uno escarmiente en cabeza ajena. Otras veces, de entre muchas brozas literarias, saca un título y un nombre, que desde ese día tienen circulación y cotizan en el mercado de los valores literarios de España (Cabezas, 1936: 181)

Y añadía comentando la variopinta lista de volúmenes recibidos para ser comentados en el folleto Museum:

...pasa de doscientos, entre libros y folletos nuevos, editados en idiomas diversos y en las siguientes ciudades: Madrid, Buenos Aires, París, Roma, Manila, Barcelona, Palma, Santiago de Chile, Ciudad de Méjico, Bogotá y Nueva York. (...) Esta simple relación dice toda la popularidad de que goza Clarín en el año 90. (...) Armando Palacio Valdés, que ha publicado este año La hermana de San Sulpicio, le aconseja sobre las condiciones que ha de exigir a "ese francés que quiere traducir La Regenta". Y de Italia y Alemania recibe proposiciones de colaboración literaria. Esto en una época en que todavía los absurdos nacionalismos y la ignorancia de los idiomas mantienen aisladas las distintas culturas de los pueblos, aún dentro de un mismo continente (Cabezas, 1936: 182).

Tal como puede notarse, es esta década del '90 cuando el "provinciano" Alas se torna "universal": su crítica pasa a concebirse como catalizador de cierto espíritu cosmopolita y renovador, capaz de juzgar con criterio de modernidad "europea" la praxis literaria de la actualidad española. Y es este período durante el cual, según Cabezas, Clarín comienza a rebasar los estanques de las fronteras: "El cacique literario

11 Tal como señala Carbonell (1994), en varios paliques aparecidos en La Publicidad, Clarín objeta la benevolencia de Valera. Llega a acusarlo de articular una estrategia hamletiana donde -fingiéndose loco- se habría ahorrado la expresión de sus verdaderos juicios estéticos sobre ciertos autores americanos. Distanciándose nuevamente de las exigencias propias de la "crítica científica", Alas reclama al erudito sinceridad en sus opiniones. Con una ironía que raya la crueldad, denuncia la inutilidad de la alabanza mutua entre el autor de las Cartas americanas y sus reseñados; y sostiene que la idea de Colón al descubrir tierra era doblar el imperio español, pero nunca centuplicar la mala poesía. 
de Oviedo empieza a irradiar su influencia más allá de los cenáculos madrileños. El provinciano Clarín empieza a ser ciudadano del mundo" (182). Y sin embargo, vale enfatizar aquí lo que se ha venido indicando en apartados anteriores: esa actualidad cosmopolita de la crítica clariniana resulta contracara paradójica de su coincidencia recurrente con el nacionalismo más conservador del criticismo erudito. Y el lugar más apto para revisar ese contraste resulta la intimidad de su pensamiento con respecto a América y a su potencial autonomía cultural.

En la recepción de la literatura americana, la crítica de Alas parece contraponer en un principio dos vías: aquella que concilia con el legado y que se asocia con Rodó; y aquella que se visualiza más bien como una postura reactiva, ligada con Darío. Clarín se sabe "intermediario" entre la periferia y el centro ("aduanero de las letras", como lo llamaría Unamuno), y es desde ese lugar que detenta un enorme poder de consagración. En términos de Casanova (2001), la crítica resulta "creadora de valor literario" (38) en tanto posee cierta autoridad debida a su pertenencia nacional: el crítico contribuye "al crecimiento del patrimonio literario de la nación que consagra" (39). Por eso Casanova sostiene que también son los críticos los "responsables de los malentendidos y los contrasentidos que caracterizan a las consagraciones centrales" (40). Buena parte de esa "ceguera etnocéntrica de los centros" (40) puede observarse en la forma polémica con que Clarín desautoriza la emergencia de Darío. Tal como señala Cabo Aseguinolaza (2012) no es casual que el término cosmopolitismo se vuelva clave en ese momento: la aparición del modernismo implicó una "reconsideración de la posición de la literatura en castellano respecto a la literatura mundial y a las literaturas europeas" (396). Lo curioso es que la forma de cosmopolitismo reivindicada por el modernismo de Darío era bien distinta a la de Alas, y se asociaba claramente con la huida hispanoamericana de aquella marginalidad hasta entonces compartida con España en torno a los ejes fundamentales de la modernidad occidental. El hispanoamericanismo de Valera o la subestimación clariniana ante la modernidad americana pueden comprenderse entonces como formas de reacción ante el latinoamericanismo "francés". Pero el verdadero poder revolucionario del modernismo dariano no consistía en la emulación de la moda parisina, sino en alterar "la propia manera de concebir la literatura española en su conjunto, a partir de la consideración por primera vez de las letras americanas en español como una realidad específica" (Cabo Aseguinolaza, 2012: 187). Lo singular de la crisis finisecular de las letras europeas coincidió para el caso español con la emergencia de un modernismo americano que interpelaba a España desde un lugar inédito. No es casual que se atacara a Darío por su "deficiente" casticismo ni que Valera subrayara el "galicismo de la mente" de su obra. El desdén hispanocéntrico frente a Darío es la consecuente respuesta ante su incómoda capacidad de "objetivar" la crisis española. Prueba de ello es la forma en que el poeta nicaragüense mide la caída de la herencia áurea en el Madrid de fines de siglo XIX:

¿Cómo hablarían ante el espectáculo de las amarguras actuales los grandes reyes de antaño, cómo el soberbio Emperador, cómo los Felipes, cómo los Carlos y los Alfonsos? Así cual ellos el imperio hecho polvo, las fuerzas agotadas, el esplendor opaco; la corona que sostuvieron tantas macizas cabezas, así fuesen las sacudidas por terribles neurosis, quizá próxima a caer de la frente de un niño débil, de infancia entristecida y apocada... (Darío, 2005: 29-30).

Darío se erige desde el seno de España como un testigo privilegiado de sus contradicciones. En su rol de outsider legitimado justamente por pertenecer a la 
periferia, impugna el desconocimiento que España tiene con respecto a América y afirma:

Gloríanse los ingleses de los triunfos conseguidos por la República Norteamericana, hechura y flor colosal de su raza: España no se ha tomado hasta hoy el trabajo de tomar en cuenta nuestros adelantos, nuestras conquistas, que a otras naciones extranjeras han atraído atención cuidadosa y de ellas han sacado provecho. En las mismas relaciones intelectuales ha habido siempre un desconocimiento desastroso (34).

Darío expresa la excepción de "un Altamira, un Menéndez y Pelayo, un Clarín" (34), pero no por ello lograría entibiar la distante respuesta de Alas. En ese mismo libro, España contemporánea, es curioso el modo en que defiende la novela española de aquellas opiniones que la dan por terminada. Su hipótesis generalizada es que la novela española perdió desde el siglo XVIII cierta característica "nacional" al haberse visto influenciada por corrientes exteriores, desde el romanticismo al naturalismo y al psicologismo. Contra esta teoría Darío esgrime que justamente "a través de la imitación ha permanecido visible el carácter nacional” (Darío, 2005: 156). Y como si no bastara esta marca ejemplar de un cosmopolitismo claramente divergente del clariniano, arriesga de forma novedosa la existencia de una divisoria de aguas entre la novela española y sus avatares "regionales":

Hoy mismo, las novelas de Salvador Rueda y Reyes son puramente andaluzas. La novela gallega nos la ha dado, aún vestida con modas extranjeras, la egregia doña Emilia; la novela vasca tendría su sola representación con esa admirable y fuerte Paz en la guerra, de Miguel de Unamuno. Existe, pues, no solamente la novela española, de Galdós, Palacio Valdés, Valera o Alas, sino la novela regional (157).

Lejos de atemperar la crisis del género "novela", la intervención de Darío enuncia fuertes tensiones del campo que permanecen subyacentes a esa misma crisis y que evocan por demás las contradicciones propias del nacionalismo español en general, y del clariniano en particular. Es evidente al respecto la alusión a dos cosmopolitismos diversos - uno ligado a la recuperación del lugar europeo de España y otro a la aceptación de la multiplicidad americana_ ${ }^{12}$; y es clara también la oblicua mención de dos nacionalismos distintos —uno supuestamente "españolista", y otro más ligado al localismo - . No se trata de indefiniciones sino de ambigüedades constitutivas del problema que implicaba en el fin de siglo la relación entre literatura y nacionalismo español. Aún más, en sus artículos sobre España de 1899 Darío recuerda la influencia francesa innegable en la narrativa española finisecular. Dentro de esa línea menciona a Leopoldo Alas como pionero de la novela de ideas y lo identifica con cierto grupo naturalista que tenía "el deseo de hacer algo nuevo, de encauzar en España la onda que venía de Francia” (158). Sin faltar a la verdad, la mención de aquel contagio

12 Zanetti (2008) ha explicado en detalle el rol del cosmopolitismo de Darío en su lucha contra el límite español: “...su cosmopolitismo le brindaba siempre un territorio escriturario, nuevo, moderno, y amenazador para la pureza del castellano según un buen número de integrantes de las élites intelectuales y políticas criollas argentinas y de las españolas" (538). A aquellos "patriotas del consonante" Darío les recordará que "el sablazo de San Martín desencuadernó un poco el diccionario, rompió un poco la gramática” (538). Según Zanetti —y en coincidencia con lo que se probará también aquí-, su constante comentario acerca del valor del cosmopolitismo provee una salida a la cuestión de la crisis hispánica antagónica a la "magistral” que da Rodó en su Ariel (1900). 
foráneo no implicaba por entonces lo mismo que había significado un lustro antes. Como si fuera poco, en artículo del 22 de septiembre de aquel año, Darío describe a Clarín como un "literato de alto valer" (Darío, 2005: 242), aun cuando se ha visto sometido "a la imposición de un público poco afecto a producciones que exijan la menor elevación intelectual" (242). El carácter satírico de Alas lo condena, según Darío, a "desperdiciar su talento ocupándose generalmente de autores cursis" (243). Esto habría dado a América una imagen falsa del profesor de Oviedo, cada vez más ajeno a la crítica y más ligado al palique.

Ante semejantes afirmaciones, no cabe duda del interés que posee la propia reseña que hace Alas del mencionado volumen España contemporánea. Allí, al decir de Clarín, el galicismo de Darío deja de se ser "mental" — como lo había indicado Valera-y pasa a ser "de corazón" (Darío, 2005: 277). Acusa a Darío de un inconveniente serio e "incurable" (277): "al educarse", dice, "se ha dejado sugestionar por la forma francesa" (277). Y añade:

Pensar, sentir, querer... Ya todos, o muchos sabemos hacerlo en europeo, más, en universal, si supiera hablar así. Declaro que me río cuando algún ácrata cosmopolita me llama estrecho, limitado, porque quiero que se respete la sintaxis castellana. Pero lo universal (que no es lo parisiense) debe cada cual, si tiene algo sólido, original, dentro, sentirlo, pensarlo y expresarlo de manera que revele más las influencias naturales, sanas, como las de raza, nación, tiempo, etc., etc., que enfermizas y violentas sugestiones circunstanciales (278).

Como puede notarse, es evidente que la fórmula superadora del "cosmopolitismo" - concepto ambiguo que había terminado por identificarse con la apertura hacia Francia- es la de lo "universal". El "provinciano universal" que es Alas no teme proponer el contraste entre Darío y los exponentes más notables de la erudición de su tiempo: Valera y Menéndez Pelayo, "que a pesar de su hondo y real casticismo, han tenido que estudiar, no diré tanto, sino mucho más (y no hay ofensa claro) que el Sr. Darío la vida y las letras extranjeras" (278). El caso del escritor americano es el de quien ha sucumbido ante "esa triste admiración genérica por lo que viene de París" (278). Al respecto concluye Clarín: "Sí; el mayor defecto de este libro, tan discreto en muchas cosas, es esa nota cursi, del mal francés que tiene inundado el espíritu de Rubén Darío" (279).

Tal como puede percibirse, la resistencia ante la emancipación literaria americana parece cifrarse en este juicio clariniano sobre el libro de Darío acerca de España ${ }^{13}$ :

13 Esto no implica restringir las complejas interrelaciones de ambos autores al solo ejemplo citado. Tensiones similares son capaces de rastrearse en buena parte de los contactos entre Alas y Darío. Ashhurst (1980) ha podido historiar en su momento los diversos estadios de la relación. En un artículo publicado en La Publicidad durante 1893 Alas había afirmado del poeta americano: "No tiene en la cabeza más que una indigestión cerebral de lecturas francesas y el prurito de imitar en español ciertos desvaríos de los poetas franceses de tercer orden..." (citado en Ashhurst, 1980: 155). A ese y otro ataques, Darío respondió poniendo a la erudición española de su parte: “...puede pedir datos sobre los que en América escribimos a algunos amigos suyos, mejor informados, como Campoamor, Nuñez de Arce, Valera, Menéndez Pelayo; sobre todo, Menéndez Pelayo" (158). Poco tiempo antes de la reseña de España contemporánea Clarín había llegado a elogiar a Darío, aunque no sin reproches. En un palique de 1900 decía: “...usted que es tan listo; y tan elegante... a la española, cuando quiere; déjese de esos galicismos internos, que son los más perniciosos. ¿Para qué ese afán de ser extranjero? Cuando a usted se le ocurran diabluras retóricas, que no sean...de París, que sean... de Santillana, donde ya sabe usted que también está el diablo" (citado en Ashhurst, 1980: 159). 
un volumen desautorizado sobre todo por su apego al encuadre francés, algo desde luego no legítimo para el análisis del campo cultural de la España de fin de siglo. La reacción ante la figura de Rubén Darío, capaz de desmarcarse de su entorno como líder inédito de un canon entendido hasta entonces como subsidiario, forma parte del rechazo más abarcador de la poesía americana en su totalidad. No es casual que el propio Clarín, tan tolerante para con otras causas, se muestre aquí más conservador incluso que la ortodoxia erudita. En sus propias palabras llega a apiadarse de Menéndez y Pelayo por haber sido condenado a escoger algo bueno en aquella "selva infinita de tanta rama" (Ashhurst, 1980: 161) que era el objeto de su Antología ${ }^{14}$. Siempre en pugna entre la reivindicación del capital literario del pasado imperial y el rol de una erudición que le era ajena, también arremetía contra Valera diciendo: "Si hubiera tantos poetas de primera clase como don Juan pretende admitir, no habría siglo de oro español ni alemán, ni francés, ni inglés, ni latino, ni griego que se comparase al siglo XIX en la América castellana..." (Ashhurst, 1980: 160). Así, contra ese fondo subestimado, Darío resultaba una alternativa no deseable de renuncia al espíritu casticista, ligada al cosmopolitismo americano y a su interés por París: contrapartida clara de la opción que encarnaba por su parte José Enrique Rodó, en consonancia con el respeto al legado peninsular y a esa asimilación conjunta de una supuesta pertenencia a la hispanidad.

Rodó es quien justamente declara en su artículo de 1899 acerca de la primera edición de Prosas profanas: "Rubén Darío no es el poeta de América" (Rodó, 1964: 163). Tal como explica Dobry (2010), la voluntad del autor uruguayo es clara: "Para Rodó la literatura en Hispanoamérica había estado tan ocupada en un "utilitarismo batallador" que hacía falta un poeta desentendido de la voluntad de ser americano para dedicarse seriamente a ser poeta" $(62-63)^{15}$. Es entendible que en esa disyuntiva el foco de Alas tendiera a posarse en la coincidencia con el autor de Ariel. Otra vez es el doblez entre lo íntimo y lo público, entre lo epistolar y la crítica, lo que define con precisión la postura "nacionalista" de Clarín. En carta del 30 de junio de 1897 Rodó le escribe:

Bien ha interpretado Ud. uno de los sentimientos en mí más intensos y poderosos, cuando en las líneas que me consagra en un periódico de Barcelona, me presenta como partidario de la unión espiritual estrechísima de España y América (citado en Ashhurst, 1980: 164).

Y el 11 de agosto Clarín le responde:

Estaba ya anhelando recibir de América cartas así, pues yo que soy muy poco patriotero, me siento muy patriota... intercontinental... Mis elogios de la Revista $\mathrm{Na}$ -

14 Es paradójico, sin embargo, que la defensa que Menéndez y Pelayo hace de Rubén Darío no lo es tanto por su novedad sino por su supuesto respeto a la tradición española. Al caso puede evocarse la famosa anécdota que cita Olguín (1957) cuando narra que en una tertulia donde alguien arremetía contra Darío y sus innovaciones métricas, especialmente contra su acentuación del endecasílabo, "D. Marcelino probó que esa forma era la de la castellanísima gaita gallega" (30).

15 En este mismo texto queda claro que la postura de Rodó responde al antiespañolismo declarado luego por Rubén Darío en su autobiografía de 1912. Allí, el nicaragüense recuerda los últimos años de la década del '90 en el Ateneo de Buenos Aires: "Yo hacía todo el daño que me era posible al dogmatismo hispano, al anquilosamiento académico, a la tradición hermosillesca (...), y ponía a más raros de Francia, de Italia, de Inglaterra, de Rusia..." (Dobry, 2010: 62). 
cional eran espontáneos y sinceros. Y para que vea usted esta sinceridad, le diré que recibí hace unos meses unos cuantos números que ya no me parecieron tan bien, pues vi con dolor en ellos demasiado $a z u l^{16}$... (citado en Ashhurst, 1980: 164).

Tal como puede verse, Rodó se dispone dentro de la genealogía clariniana de la hispanidad en el rol del descendiente que acepta acatar las continuidades. Tal como explica García Morales (1992) en su libro al respecto, Rodó se muestra de acuerdo con el intento modernista de renovación formal siempre y cuando la literatura no olvide sus exigencias con otros intereses de la vida moderna. Este prurito ético es el que lo acerca bastante a Clarín, más allá de la coincidencia también con respecto a la falta de americanismo que Darío mostraba, ya sea olvidando los "temas" americanos según Rodó exigía, como pecando de "afrancesamiento" según Alas denunciaba. En este sentido no sorprende la voluntad de Rodó por difundir hacia 1897 un concepto totalmente distinto de modernismo, entendido ahora como manifestación de anhelos superiores a los expresados por "los logogrifos del decadentismo gongórico y las ingenuidades del decadentismo azul" (citado en García Morales, 1992: 13). Es evidente que las semejanzas con el pensamiento clariniano eran de cierto modo una estrategia de posicionamiento para este modernismo alternativo. Su efectividad en cuanto al juicio de Alas puede notarse en la propia carta que este devuelve desde Oviedo con su opinión sobre la Revista Literaria que dirigían Rodó y Pérez Petit. Allí afirma:

A Uds. principalmente aludo cuando espero que haya una parte de la juventud de la América española que muestre el generoso cosmopolitismo más que en el arte (...) en la religión, en la filosofía, en lo que se llama ciencia (citado en García Morales, 1992: 16).

Una vez más el concepto de cosmopolitismo, imbricado en la intimidad epistolar, enuncia la tarea cartográfica del nacionalismo clariniano: frente al nocivo "cosmopolitismo" francés - capaz de sustraer el capital literario otrora dependiente de España para acumularlo en su propio afán de exclusividad-, se sugiere un cosmopolitismo "generoso", ya no ligado a la biblioteca sino más bien a la filosofía y a la ciencia; es decir, a las influencias generales de la erudición europea. Esto se explica con toda claridad en el prólogo que Alas escribe justamente para el Ariel de Rodó. Allí el "galicismo" como amenaza ya no es ni mental ni de corazón: "hombres de positivo talento y cultivado espíritu se dejaron llevar por la corriente del galicismo integral", señala (en Rodó, 1910: viii). La moda de París sólo podrá aplacarse si efectivamente los intelectuales americanos retornan al legado hispánico. Porque a pesar de la fuga, afirma Clarín que

...también es verdad y ventura que en el seno de esa misma juventud literaria americana aparecen síntomas de una favorable y justa reacción, en armonía con

16 Alas atacó a Darío incluso antes de leerlo. Sin embargo, el elogio a Rodó muestra la preferencia en su verdadera motivación. Tal como señala Dobry (2010), "Clarín salva la figura de Rodó, ya que "los dolores de la separación" no debían borrar "la sugestión española" que subyace a la literatura del continente. Es significativo que Clarín no se refiera a españoles e hispanoamericanos sino a "españoles peninsulares" y "españoles americanos"; en ambas márgenes percibe la amenaza afrancesada de los azules" (68). 
análogas corrientes en otros órdenes de la vida; reacción que vuelve los ojos a España, sin desdecirse del pasado (ix).

Ahora bien, cabe preguntarse si el doblez clariniano entre la íntima opinión y la pública exhibición del juicio crítico no constituye para América un derrotero binario cuya tercera vía estaría marcada en realidad por el silencio. Porque ese silencio abriría finalmente el espacio para la pregunta por Martí. Entre la diferenciación con la antigua metrópoli y el sometimiento asimilador a la hispanidad, la variable de Martí podría proyectar la interrogación acerca de una tercera vía que curiosamente el crítico Leopoldo Alas silencia no sólo a lo largo de su obra sino también de su epistolario.

Tal como puede concluirse del trabajo de Lissorgues (1979) sobre Clarín y el problema cubano, sus intervenciones frente a tal tema constituyen un recorte notable para pensar el particular "nacionalismo" que sostiene frente a la cultura americana. $\mathrm{Su}$ insistencia pasa por "la necesidad de conservar la unidad indestructible entre España y América" (Lissorgues, 1979: 49). Tal como allí se recoge, Clarín se deja arrastrar por cierta exaltación patriota no distante de la concepción intrahistórica de Unamuno. Llega a afirmar que el pueblo va a morir a Cuba "por amor a España, porque la voluntad nacional quiere de veras, en serio, callada, elocuente con la sangre, defender nuestro dominio en Cuba" (en Lissorgues, 1979: 60). Aunque expresa en reiteradas oportunidades su conciencia de que los sabios y las clases directoras que organizan la opinión no son quienes van a la guerra, su reacción está lejos del antibelicismo. De hecho, en palabras de Lissorgues:

...Los insurrectos son, para Clarín, españoles extraviados que "cometen un crimen de leso patriotismo no queriendo ser españoles". Y al respecto, distingue dos categorías: por una parte, "los que pueden ser cuerpos extraños que, luchando por la independencia de Cuba, pretenden sencillamente robarnos un pedazo de territorio", y por otra "los que son tan españoles como nosotros, aunque extraviados por la locura del separatismo". ¿Pero qué son esos cuerpos extraños? (...) ¿Se alude con esa expresión a los exiliados cubanos (entre los cuales figura José Martí hasta 1895) a quienes, tal vez, la prensa oficial designa así por razones de propaganda? (68).

Lissorgues cree que con el tiempo Clarín deja de considerar dos tipos de insurrectos y acepta finalmente la identificación oficial de los rebeldes con simples "ladrones". Esa tercera vía que elige una ruptura radical con la hispanidad (ya no sólo en lo literario sino en la más concreta territorialidad) niega las opciones de asimilación y también de emancipación literarias que se han venido mencionando para los casos de Rodó y de Darío. Esta idea prodigaría varias hipótesis acerca de las razones del silencio clariniano sobre Martí. Y otras tantas pueden también extraerse de su revés: el escritor cubano sí hace mención de Alas y de su literatura en numerosas oportunidades.

En apuntes de la década del ' 80 Martí resume con aspereza su opinión sobre $L a$ España Moderna. De aquella mítica revista dice:

Con el engaño de la literatura se nos está entrando por América el espíritu español, que de seguro no podrá hacer en casa ajena sino lo que hace en la propia, lo cual es, según el español Mallada, esa gran maravilla de tener las mejores aceitunas, y 
hacer el peor aceite (...). Imitan lo bueno que tienen, para publicar una revista al mes, y la llaman "La España Moderna”, cuando si lo fuese de veras, no la habrían llamado así... (Martí, 1964a: 183).

Y ante ese peligro "territorial" que implica la incidencia literaria española, Martí se detiene en las características de sus principales autores: "La Pardo escribe su español airoso. Echegaray, con rayos. Galdós, el agua clara que corre entre guijas. Palacio Valdés, sincero...” (184). La lista continúa con un detalle preciso que enjuicia a cada autor (de manera favorable para Menéndez y Pelayo, por ejemplo; irónica para Valera), y culmina con el curioso suspenso sobre Alas: "Y Clarín;" (184).

Tal vez pudiera pensarse esa repentina omisión justamente como una respuesta azarosa a lo que luego sería el silencio de Alas sobre el escritor cubano. Sin embargo parece más acertado echar luz sobre ese vínculo evocando opiniones expresas de Martí acerca de Clarín. Madrid los había hecho coincidir durante los años '70 en la tertulia de la Cervecería Inglesa: no queda, sin embargo, vestigio significativo de aquel cruce. En un artículo publicado en La Opinión Nacional el 17 de abril de 1882, Martí reseña el libro Solos de Clarín:

Cuando se leen los diarios de Madrid, suele hallarse en ellos unos buenos artículos que tienen de grave y de chispeante, en que se juzga con buen sentido y gracia los dramas que se representan y los libros que se publican en la Corte, los cuales artículos llevan la firma de un "Clarín", que es el nombre de batalla del buen crítico Leopoldo Alas (...). Su crítica es sensata y generosa; y saca a lucir lo bueno, antes de censurar lo que halla malo. (...) Y cada autor está allí como es de veras, y lo llano del lenguaje de "Clarín" no obsta para que con él, como con cuchilla de cortante acero, vaya sajando y cerrando y purgando por los libros, hasta dar con la razón real de ellos... (Martí, 1965: 266).

Sin embargo, pocos años después, en carta del 14 de septiembre de 1888, Martí confiesa a Manuel Mercado que reconoce en el mexicano Puga y Acal

...cierto odio de caballero a la crítica brutal, de callos y caracoles, que en España priva ahora, y en otras tierras además de España, donde copian lo peor de Clarín, que dista de Larra, a quien lo asemejan, lo que dista en su pueblo un aguador de un duque, y en lo mejor no es lo que parece, porque la idea es delgada como un hilo; y para la forma mete los brazos hasta el hombro en Quevedo. Su novela La Regenta sí es buena ${ }^{17}$, aunque empiece hurtando a Thackeray, y debían distribuirla gratis los gobiernos en los pueblos católicos (Martí, 1964b: 135).

La "sensatez" clariniana ha pasado en un lustro a convertirse en modelo de crítica brutal que invade España y otras tierras fuera de ella: avatar literario de la "expan-

17 Mucho debe haber impresionado a Martí la lectura de esta novela. Todavía la recuerda en su diario haitiano de 1895. Allí comenta haber hallado entre volúmenes olvidados un libro titulado Las Madres Cristianas de Contemporáneos Ilustres. A propósito de sus temas reflexiona sobre la idea de sociedad autoritaria como aquella que se basa en la desigualdad humana, donde "se exige el cumplimiento de los deberes sociales a quienes se niegan los derechos, en beneficio principal del poder y placer de los que se los niegan" (Martí, 1964c: 204). Y menciona que en el libro se habla mucho de Margarita Bosco "que es madre de cardenal, que recuerda mucho la del cura mimado de La Regenta, de Alas, aquel cura sanguíneo a quien la madre astuta le ponía la cama y la mesa” (104). 
sión" nacionalista española, Martí rechaza el ejercicio destructivo de una crítica que pocos años después esgrimiría sus armas contra el propio modernismo americano. Claramente no ha pasado sólo tiempo entre una y otra mención: ha cambiado en Martí su pensamiento político y con él la objetivación de sus antiguos lazos culturales con la intelectualidad española. En este sentido, los viejos modelos críticos que conociera durante su primera deportación en la península pierden significativo valor fuera de las zonas que el escritor cubano reconoce en ellos como progresistas. Es por ello que Alas, según Martí, sólo vale en tanto autor de La Regenta: su crítica en cambio buscaría revestirse de la mordacidad quevediana, fracasando como remedo degradado de Larra. La íntima opinión vertida en esa carta es ya la del intelectual comprometido de lleno con la organización del movimiento de revolucionarios cubanos en el exilio estadounidense: desde su óptica no sería posible conciliar con un autor que desde entonces venía defendiendo la hispanidad de Cuba. La postura independentista de Martí, claro está, le obligaría a reaccionar desconociendo radicalmente aquella misma zona que no por casualidad había legitimado a Clarín como custodio del canon nacional: su praxis crítica como modelo sagaz, irónico y sobre todo, peligrosamente expansivo.

\section{A modo de conclusión}

Tal como puede observarse hasta aquí, es factible revisar la crítica clariniana en su faceta catalizadora de radicalidades nacionalistas que surgen ante ciertos temas como la importancia del legado del Siglo de Oro para la redención finisecular del XIX, o el peligro de la "fascinación" americana con París. Posturas eruditas conservadoras como las de Valera o Menéndez y Pelayo promueven no sólo la canonización de cierto corpus áureo, sino también la asimilación de la novedosa producción americana bajo la cúpula abarcadora de la "hispanidad". En este sentido, y a pesar de su perspectiva renovadora y "cosmopolita", la reacción de Clarín frente a la emergencia de Darío - y a la preferencia por Rodó - demuestra cierto matiz nacionalista en uno de los autores a priori menos ligado con la defensa a ultranza del nacionalismo literario español. Su nostalgia por cierto recorte de la literatura imperial resulta en Alas contracara de la pérdida colonial que España experimenta a las puertas del siglo XX. América, en ese sentido, también se vuelve tema crítico muchas veces traducido en la intimidad epistolar como territorio literario que - en palabras del propio Alas - alimenta su patriotismo intercontinental. La ambigüedad misma de esta noción ubicada entre lo nacional y lo universal, logra actualizar los sentidos políticos ineludibles que se configuran en torno al eje nacionalismo-erudición. Tal como puede extraerse de los temas que se han estudiado en estas páginas, las coordenadas de construcción erudita del canon y de la historia literaria nacional en la España de fines de siglo XIX ayudan a enmarcar específicamente las modalidades propias de la praxis clariniana en la contienda crítica finisecular. Puede identificarse entonces la tensión implícita de su bifrontalidad entre una supuesta ajenidad ante la herencia literaria imperial (recorte fundacional para el historicismo erudito de su contexto), y un deseo recurrente de incidir en la valoración del pasado cultural de España, y de hacerlo por medio de una lectura que lo relativizara en la modelación del presente (época controvertida para el sostén de la "filiación" americana). En este plano, entonces, pueden afirmarse al menos tres elementos conclusivos: 1) por un 
lado, el doblez que la intimidad de ciertos textos epistolares de Alas exhiben con respecto a sus opiniones públicas sobre la construcción del canon erudito; 2) por otra parte, la contradicción entre su rol como crítico de actualidad - dispuesto siempre al cosmopolitismo innovador del europeísmo- y su nostalgia recurrente por el canon imperial (más afín al nacionalismo de la especialidad erudita y a la retención de la autoridad normativa sobre la cultura americana); 3) y por último, el arco de consensos paradójicos en su esporádica adhesión a modelos eruditos conservadores - como Menéndez y Pelayo o Valera-.

En la cohesiva apertura de este abanico de asuntos puede sin embargo concebirse un asedio cada vez más ajustado al modo con que Clarín delimitó sus responsabilidades lectoras de actualidad en constante negociación con lo que entendía como una especificidad alterna de la crítica literaria y que era ni más ni menos que la competencia de la erudición, campo de valoración legitimada del pasado literario y origen del perfil cultural del nacionalismo hispano. Las sorprendentes cercanías que ciertos aspectos de su obra presentan con el campo erudito permiten afirmar la idea de una semejanza ideológica en cuanto a la defensa nacionalista de la hispanidad. Así, la reacción conservadora de Clarín frente al modernismo americano descentra el canónico progresismo con el que suele asociarse su figura en otros planos.

En esta línea, no es casual que sea Martí - modelo curiosamente omitido en la geografía "literaria" que dispone Alas - quien ataque frontalmente la crítica clariniana como "expansión" hegemónica de un modelo "brutal" acaparador de España y de otras naciones foráneas. Tal vez así lo haya percibido Darío, cuando en ocasión de escribir la necrológica del poeta cubano publicada en La Nación el $1^{\circ}$ de junio de 1895, exclamaba:

¡los tambores de la mediocridad, los clarines del patrioterismo, tocarán dianas celebrando la gloria política del Apolo armado de espadas y pistolas, que ha caído, dando su vida, preciosa para la humanidad y para el Arte, y para el verdadero triunfo de América (...)! (citado en Zanetti, 2008: 524).

Darío enfatiza a partir de este punto la lucha modernista "contra el sometimiento del artista a los imperativos de la nación" (citado en Zanetti, 2008: 524). En esta senda es factible afirmar que uno de los primeros reclamos de autonomía intelectual frente a las exigencias de cualquier nacionalismo hubo de darse en América. El caso que aquí se ha expuesto con respecto a la crítica clariniana y a sus límites no es más que una faceta minúscula de la enorme hispanidad que aquel conjunto notable de poetas americanos debió trascender para conquistar su territorio propio de existencia.

\section{Obras citadas}

Alas, Leopoldo, Rafael Calvo y el teatro español, Madrid, Librería de Fernando Fe, 1890. Disponible en: <http://www.bnc.cat/digital/arca/castella/index.html >.

—, Nueva campaña, en Crítica. Obras completas, t. IV, vol. I, Oviedo, Nobel, 2003a, pp. 704-911.

—, Sermón perdido, en Crítica. Obras completas, t. IV, vol. I, Oviedo, Nobel, 2003b, pp. 476-661.

—, Obras completas, t. II, Madrid, RBA Editores, 2008. 
Álvarez Junco, José, Mater dolorosa. La idea de España en el siglo XIX, Madrid, Taurus, 2005.

Ashhurst, Wayne, La literatura hispanoamericana en la crítica española, Madrid, Gredos, 1980.

Cabezas, Juan Antonio, Clarín, el provinciano universal, Madrid, Espasa Calpe, 1936.

Cabo Aseguinolaza, Fernando, Historia de la literatura española. 9. El lugar de la literatura española, Barcelona, Crítica, 2012.

Campos López, Ronald, "Primeros promotores de la idea de hispanidad: Darío, Menéndez Pelayo, Valera, Altamira y Unamuno", Káñina. Revista de artes y Letras, XXXIX.1 (2015), pp. 33-51.

Carbonell, María Cristina, "La polémica en torno a las Cartas americanas (1889) de Juan Valera", en Actas del XXIX Congreso del Instituto Internacional de Literatura Iberoamericana, Barcelona, P.P.U., 1994, pp. 157-173.

Casanova, Pascale, La República Mundial de las Letras, Barcelona, Anagrama, 2001.

Darío, Rubén, España contemporánea, Madrid, Visor, 2005.

Del Valle, José, "Historical linguistics and cultural history. The polemic between Rufino José Cuervo and Juan Valera", en The Battle over Spanish between 1800 and 2000. Language ideologies and Hispanic intellectuals, London, Routledge, 2002.

Dobry, Edgardo, "Panamericanismo, hispanidad, nacionalismo argentino", Olivar, 11.14 (2010), pp. 61-70.

García Morales, Alfonso, Literatura y pensamiento hispánico de fin de siglo: Clarín y Rodó, Sevilla, Secretariado de Publicaciones de la Universidad de Sevilla, 1992.

Gullón, Ricardo, “Clarín, crítico literario”, en J. Ma Martínez Cachero (ed.), Leopoldo Alas “Clarín”. El escritor y la crítica, Madrid, Taurus, 1978, pp. 115-146.

Lissorgues, Yvan, "España ante la guerra colonial de 1895 a 1898: Leopoldo Alas (Clarín), periodista, y el problema cubano", en Hommage à Juan Marinello et Nöel Salomon: Cuba, les étapes d'una libération. Actes du Colloque Internacional des 22-24 novembre 1978, Toulouse, Université de Toulouse, 1979, pp. 47-76.

Litvak, Lily, "La idea de la decadencia en la crítica antimodernista en España (1888-1910)", en España 1900. Modernismo, anarquismo y fin de siglo, Barcelona, Anthropos, 1990, pp. 111-127.

Martí, José, Obras completas, t. 15, La Habana, Editorial Nacional de Cuba, 1964a.

—, Obras completas, t. 20, La Habana, Editorial Nacional de Cuba, $1964 b$.

—, Obras completas, t. 23, La Habana, Editorial Nacional de Cuba, 1965.

Menéndez y Pelayo, Marcelino, Leopoldo Alas y Miguel de Unamuno, Epistolario, Madrid, Ed. Escorial, 1943.

Núñez Seixas, Xosé Mantel, "Nación y nacionalismos en España, siglos XIX y XX”, en José Álvarez Junco y Adrián Shubert (eds.), Nueva historia de la España contemporánea (1808-2018), Barcelona, Galaxia Gutenberg, 2018, pp. 267-297.

Oleza, Joan, "Clarín y la tradición literaria”, Ínsula, 659 (2001), pp. 22-25.

Olguín, Manuel, "Menéndez Pelayo y la Literatura Hispanoamericana”, Revista Iberoamericana, XXII (enero-junio 1957), pp. 27-39.

Pozuelo Yvancos, José María, “Popular/culto, genuino/foráneo: canon y teatro nacional español”, en Theatralia III. Tragedia, comedia, canon. (III Congreso Internacional de Teoría del Teatro, 2000), Vigo, Universidad, Facultad de Filología y Traducción, Ediciones del Área de Teoría de la Literatura, 2000, pp. 235-260.

Rodó, José Enrique, Ariel, prólogo de Leopoldo Alas “Clarín”, Valencia, Ed. Prometeo, 1910.

_., "Rubén Darío”, Obras selectas, Buenos Aires, El Ateneo, 1964, pp. 163-198. 